\title{
Comparison of Creativity and Self-Esteem in Students with Employed and Household Mothers
}

\author{
Maryam Safara ${ }^{1}$, Zeinab Blori Alkaran ${ }^{2}$, Mojtaba Salmabadi ${ }^{3,4} \&$ Najmieh Rostami ${ }^{2}$ \\ ${ }^{1}$ Women Research Center, Psychology Department, Alzahra University, Tehran, Iran \\ ${ }^{2}$ General Psychology Azad University, Tehran, Iran \\ ${ }^{3}$ Family Counseling, Allameh Tabataba'i University, Iran \\ ${ }^{4}$ Farhangian University, Birjand, Iran
}

Correspondence: Maryam Safara, Women Research Center, Psychology Department, Alzahra University, Tehran, Iran. Tel: 98-218-569-2080. E-mail: m.safara@alzahra.ac.ir, safara_maryam@yahoo.com

\author{
Received: May 27, $2016 \quad$ Accepted: July 6, $2016 \quad$ Online Published: January 30, 2017 \\ doi:10.5539/ies.v10n2p63 URL: http://dx.doi.org/10.5539/ies.v10n2p63
}

\begin{abstract}
Objective: The present study was carried out to compare creativity and self-esteem in the university students with employed and household mothers in academic years 2014-2015. Method: This research is a descriptive one which is of comparative-casual type. The statistical population includes all undergraduate students of Azad universities of Roudhen, Shahr-e Ray Central Tehran and national universities of Al-Zahra, Shahid Beheshti and Vali-e Asr that among them 240 students (120 males and 120 females) were selected by random and available sampling method. To collect the data, Arjmand's (2003) questionnaire of creativity and Copper-Smith's (1967) self-esteem questionnaire were used. To test the hypotheses, independent t-test was used. Findings: The results showed that there is a significant difference between self-esteem in students with employed and household mothers. Also, a significant difference was not observed between the rate of creativity in students with employed and household mothers. Conclusion: The results of the present research can be used to provide proper strategies for mothers, instructors, and those who are relevant with educational affairs to enhance the quality of education, to nurture and flourish creativity and self-esteem in individuals.
\end{abstract}

Keywords: creativity, self-esteem, mothers, students

\section{Introduction}

\subsection{Statement of the Problem}

In psychology and logic literature, the issue of creativity is addressed in subject of intelligence, thinking and argument. Today, scientists have recognized the value and importance of creativity for individual and society, and have emphasized on it. They believed that knowledge, art and technology are the products of human creativity (Nofersti and Moein al-Ghorabaei, 2010). Also, human culture and civilization, however, are the result of the endeavors of all human beings, but its immensity and richness owes the creative individuals, thinkers, genius people, discoverers and inventors. Therefore, the importance of recognizing and nurturing these individuals becomes clear. In the current complex world in which we witness very condensed competitions of different communities to achieve modern technologies and power resources, the creative individuals with new thoughts, like the expensive capitals, have eminent positions, because the more the world in which we live becomes complex, the need to recognize and nurture the creative minds becomes clear and sensible (Abedi, 1993). According some researchers including Baron (2003), creativity is a structure that has mixed with cognitive and emotional components. Sternberg and Grigorenko (2003) have stated that creativity is not a one-dimensional concept; they believed the cognitive and emotional multi-dimensional abilities are the factors of emerging creativity. Sternberg introduces the creativity as thinking about affairs in an unusual method and reaching the unique ways.

\subsection{Importance of the Problem}

In addition to creativity, one of the factors that encourages the individual to act effectively and to be serious and hardworking id his/her self-esteem; and paying attention to this issue is also important, because in a community 
that the individuals have high self-esteem, they can be strong and stable against various tensions, mental stresses, events and sudden problems. Otherwise, lack of self-esteem leads to lack of commitment and responsibility, lack of ability to create a healthy relation, lack of control and dominance on thoughts and emotions, absence the sense of usefulness, purposefulness and self-conscious. Also, people who have low self-esteem overlook their goals and let others make decision (Yarmohammadian, 2006). Self-esteem is a kind of opinion that gives the individual this ability to have his/her real and positive view toward the self and causes that the individual confides his/her abilities and the sense of the control of self-esteem give the person this possibility to control and manage his/her life (Kiamarsi, Ariaporan, \& Abolghasemi, 2013). According to the newest definitions, self-esteem includes the growth of self-evaluative emotions by the person and the sense of attractiveness and qualification (Ourerson \& Jost, 2007).

Since a direct research has not been done about the comparison of creativity and self-esteem in student with employed and household mothers, here some similar researches are mentioned. Rohollahi (1998) in a study aiming at the investigation and comparison of academic achievement of Guidance school students with employed and household mothers in Tehran showed that the academic achievement of students with employed mothers is more than that of students with household mothers. Moddaberi (2004) in his research entitled "the effect of the parents' job on self-esteem in pre-university female students" showed that the girls with employed mothers have higher self-esteem. In other words, being employed the parents is effective on girls' self-esteem. Arjmand (2003) in a study on the relationship of parents' job and their children's creativity showed that there is no significant relationship between parents' job and creativity in their children.

\subsection{Review of the Literature}

Peyvastehgar, Dastjerdi, and Dehshiri (2010) in a study showed that the rate of creativity in young male group is higher than young female group. Hassanzadeh and Imanifar (2007) in a research aiming at studying the relationship between creativity and self-esteem with academic achievement in adolescents and the youth showed that there is no significant relationship between creativity and self-esteem with academic achievement in students. Yarmohammadian (2006) in a study to measure the relationship of self-image and self-esteem in creative and non-creative university students showed that the creative students obtained better scores in two variables of self-image and self-esteem than non-creative students. In sum, the results showed that there is a significant relationship between self-image and self-esteem of each group.

It is imagined that mother [or step-mother] has the pivotal role in strengthening self-esteem and creativity. If the mother and child have a healthy relationship, that is, the child feels that his/her mother is able to react his/her emotions and needs immediately and effectively and understands them, s/he will have a positive sensation about self and her/his abilities in adultness. The reverse of this issue is true in the case of weakness of the relationship of mother and child. Failure in creating emotional attachment to mother can lead to permanent anxiety resulting from inattention or elimination. The signals that children receive from important surrounding people about themselves during the time are important for them (Arab-Saveji, 1999). Since the individuals' social activities, especially women's social activities, have considerably increased nowadays, some mothers due to better economic situation can better satisfy the material needs of their children, consequently the child looks for some of her/his needs such as the sense of belonging, respect and self-esteem along with her/his material needs and achieves higher self-esteem by elimination of them (Arab-Saveji, 1999). On the other hand, since self-esteem and creativity both have roles in the quality of individuals' actions and behaviors and are effective in their general, physical and mental health, and according to this issue that inattention to the university students' problems and lack of mental health of this stratum of the society that are the human capital and future staffs of the country's treatment and health organization will have undesirable effects on the health of the society, paying attention to these issues are very important, that is, what that are considered in the present study.

\subsection{Research Question}

The present study was carried out to compare the creativity and self-esteem in students with employed and household mothers; and the researcher is seeking to answer this question that "is there any significant difference between the creativity and self-esteem in students with employed and household mothers?"

\section{Method}

The present study is a descriptive one which is of comparative-casual type. The statistical population of this research includes all undergraduate students of national universities and students of Islamic Azad universities of Tehran. The sample consists of 240 male and female students of Azad universities of Roudhen, Shahr-e Ray Central Tehran and national universities of Al-Zahra, Shahid Beheshti and Vali-e Asr that were selected by random and available sampling method. To test the hypotheses, independent t-test was used. To collect the data, 
the following questionnaires were used:

1) The questionnaire of creativity: This questionnaire that was developed by Arjmand (2003) and at the beginning included 111 items that among them 75 items each with five options which had higher correlation in a pilot study were selected. To calculate the validity of the researcher-made creativity test, this test was correlated with 60-item creativity test developed by Abedi (1993) and the correlation coefficient obtained equal to 0.512; therefore, the reliability of the researcher-made questionnaire was 0.95 and its validity was 0.51 . In the present study, the reliability was obtained equal to 0.81 using Cronbach's alpha.

2) Copper-Smith self-esteem questionnaire: This questionnaire that was developed by Copper-Smith (1967) and includes 58 items that eight items are lie-detectors. Scoring is done as zero and one. To prepare this questionnaire at first, open-ended questions were used and then the final questionnaire was developed according to the obtained results and doing factor analysis. The test cut-off score is 25.4 that the individual with a score higher than mean have high self-esteem and the individual with a score lower than mean have low self-esteem. In a research the internal correlation of the self-esteem questionnaire was reported equal to 0.8 using Cronbach's alpha and its validity equal to 0.76 using Gatman's two-half method (Motamedi, 2006). In the present study, the validity was obtained equal to 0.78 using Cronbach's alpha.

\section{Results}

Table 1 shows the statistical characteristics including mean and standard deviation of scores of creativity and self-esteem in the subjects and also the characteristics of each of scales in both groups.

Table 1. The mean and standard deviation of scores for creativity and self-esteem in the students in two groups

\begin{tabular}{lccc}
\hline Variable & Group & $\mathrm{M} \pm \mathrm{SD}$ & Cronbach's alpha \\
\hline Creativity & Employed & $57.66 \pm 14.26$ & 0.89 \\
& Household & $54.95 \pm 13.73$ & 0.89 \\
& Total & $56.35 \pm 14.08$ & 0.89 \\
Self-esteem & Employed & $10.50 \pm 2.57$ & 0.54 \\
& Household & $10.93 \pm 2.91$ & 0.70 \\
& Total & $15.06 \pm 3.36$ & 0.62 \\
\hline
\end{tabular}

Table 2. Statistical parameters of self-esteem in both groups

\begin{tabular}{lcccc}
\hline Groups & $\mathrm{X}$ & $\mathrm{S}$ & $\mathrm{SD}$ & $\mathrm{T}$ \\
\hline Employed mothers & 37.63 & 5.56 & 0.85 & 3.088 \\
Household mothers & 34.20 & 6.58 & 0.72 & \\
\hline
\end{tabular}

The results of show that the calculated t-test (3.088) with 118 degrees of freedom and confidence level of $1 \%$ (2.35) is higher than t-value of table, therefore, there is significant difference between self-esteem of student with employed mothers and those with household mothers.

Table 3. Statistical parameters of creativity in both groups

\begin{tabular}{lcccc}
\hline Groups & $\mathrm{X}$ & $\mathrm{S}$ & $\mathrm{SD}$ & $\mathrm{T}$ \\
\hline Employed mothers & 267.62 & 29.93 & 3.86 & \\
Household mothers & 256.70 & 32.48 & 4.19 & 1.915 \\
\hline
\end{tabular}

The results of the above table show that the calculated t-test (1.915) with 118 degrees of freedom and confidence level of $1 \%$ (2.35) is less than t-value of table, therefore, there is no significant difference between creativity of student with employed mothers and those with household mothers.

\section{Discussion and Conclusion}

The present study was done to investigate the relationship between creativity and self-esteem in university students with employed and household mothers. The first finding of the research showed that there is a significant relationship between self-esteem in students with employed and household mothers that this result is 
in agreement with previous researches including Modabberi (2004) and Rezaei (2010). Rezaei (2010) in his research showed that there is a significant difference between self-esteem and mental health in employed and unemployed mothers. In explaining this result it can be said that the employment of mother can increase the self-esteem of mother through increasing the family's income, little discrimination between the roles of men and women and creating a positive pattern in favor of boys and girls in their lives. On the other hand, employed mothers have less time to allocate to home activities and children than household mothers and this will cause the children with employed mothers are dependent to their abilities in doing their affairs and activities, as a result their self-esteem is increased. Consequently, all above factors indicate the difference in self-esteem in children having the employed mothers with children having unemployed mothers.

Also, the findings showed that there is no significant difference in rate of creativity the students with employed and household mothers that this finding is compatible with that of previous researches including Arjmand (2003), who showed there is no significant relationship between the job of parents and creativity of children; but it is contrary to that of Narimani, Ghasempour, Hosseinpour, and Cheleh (2011), who showed that culture is an effective factor in creativity and to study the creativity we must pay a great attention to culture. In explaining this finding we can say that the creativity of students is affected by culture of society rather than be related to the job of their mothers.

Some of the limitations of the present study were the high number of the items of the questionnaire that caused the participant not answer the questionnaire completely and some students' lack of tendency to contribute doing this research; also this study was done about the available subjects that its results must be generalized to the other students with caution. At the end, it is suggested that another similar research is done to investigate the role of the other relevant factors which may intervene in this field. Therefore, according to the importance of the creativity and self-esteem rate in individuals and as a strong base for continuity of learning and success in all fields of life, it is better the universities pay special attention to these issues, and provide a background for advent of creativity and self-esteem in students by preparing the appropriate conditions and eliminate the obstacles to achieve them.

\section{References}

Abedi, J. (1993). Creativity and new methods in its measurement. Journal of Psychology Researches, 2(1\&2), 54-64.

Arab-Saveji, A., (1999). The study of the relationship between employment of mothers and academic achievement in high school female students in city of Saveh. Journal of transitional psychology, 6(3), 2-9.

Arjmand, E. (2003). Construction and standardization of creativity measurement test (Master's thesis, Islamic Azad University of Roudehen).

Baron, R. (2003). Giftedness According the Theory of successful intelligence. In N. Colonel, \& G. Davis (Eds.), Handbook of Gifted Education (pp. 88-99). Boston MA: Allyn and Bacon.

Beyabangard, E. (2001). The methods of increasing self-esteem in children and adolescents. Journal of Psychology, 7, 3-5.

Coopersmith, S. (1967). The antecedents of self-esteem, San Francisco, freeman. Self-esteem. IOWA State University, University Extension

Hassanzadeh, R., \& Imanifar, P. (2007). The relationship of creativity and academic achievement in adolescents and the youth. Journal of sociology studies on the youth, 3, 5-7.

Kiamarsi, A., Ariaporan, S., \& Abolghasemi, A. (2013). Relationship of the symptoms of personality disorders with procrastination and educational self-esteem of female university students. Journal of social psychology, $8(28), 41-52$.

Moddaberi, A. (2004). The effect of the parents' job on self-esteem in pre-university female students. Journal of transitional psychology, 2, 120-135.

Narimani, M., Ghasempour, A., Hosseinpour, L., \& Cheleh, B. (2011). Emotional intelligence and life satisfaction in employed and unemployed women. $7^{\text {th }}$ national conference on professional health, Qazvin, Qazvin University of Medical Sciences.

Nofersti, A., \& Moein Al-Ghorabaei, F. (2010). Emotional intelligence and creativity in university students. Journal of transitional psychology, 7(36), 175-189.

Ourerson, C., \& Jost, M. (2007). Understanding Children Self-esteem. IOWA State University, University 
Extension.

Peyvastehgar, M., Dastjerdi, E., \& Dehshiri, Gh. (2010). The relationship of creativity and mental well-being in university students. Journal of behavioral sciences, 3(4), 207-213.

Rezaei, L. (2010). The effect of self-esteem on mental health in the women employed Siemens Factory in Shiraz and unemployed women. Journal of the novels in organizational industry psychology, 1(3), 19-29.

Rohollahi, M. (1998). The investigation and comparison of academic achievement of Guidance school students with employed and household mothers in Tehran. Journal of educational psychology, 4, 119-123.

Sayonchi, R., Zabihi, H., \& Ghasemi, B. (2013). The comparison of creativity and the spirit of entrepreneurship of athlete and non-athlete students. Journal of work and society, 155, 33-35.

Sternberg, R. J., \& Grigorenko, E. L. (2000). Teaching for successful intelligence. Arlington Heights, I.L: Skylight.

Yarmohammadian, A. (2006). Relationship of self-image and self-esteem in creative and non-creative university students. Educational and Psychological Journal of Sistan and Baluchistan University, 4, 109-122.

\section{Copyrights}

Copyright for this article is retained by the author(s), with first publication rights granted to the journal.

This is an open-access article distributed under the terms and conditions of the Creative Commons Attribution license (http://creativecommons.org/licenses/by/4.0/). 